\title{
IMMUNITY TO RUBELLA AMONGST SERVICE PERSONNEL
}

\author{
MAJOR I ALEXANDER, MRCOG, RAMC \\ CAPT E M SLATTERY, MTD, SRN, SCM, QARANC \\ Louise Margaret Maternity Hospital, Aldershot
}

\begin{abstract}
SUMMARY: The effectiveness of present Service policies for the screening of personnel for susceptibility to Rubella infection has been evaluated and recommendations made for improving the system.
\end{abstract}

\section{Introduction}

This survey was designed to assess the efficiency of policies for the screening of Servicewomen and Medical personnel for susceptibility to Rubella infection.

The causal relationship between maternal Rubella and congenital defects has been clearly established and extensively reviewed in the literature ${ }^{1}$. The disease has a worldwide distribution, being endemic in Western Europe. Epidemicity is variable with major outbreaks occurring every nine to ten years in the United Kingdom, whilst there is an increased annual incidence every three to five years. The disease is not generally notifiable and the variations in signs and symptoms, plus the occurrence of subclinical infection, makes accurate estimations of incidence impossible without widespread serological surveys. The teratogenic potential of this disease has demanded adequate preventive measures in the form of Rubella vaccination for seronegative women. Since 1970, Department of Health and Social Security (DHSS) policy has been to vaccinate schoolgirls between the age of 11 and 14 years. The guidelines were widened in 1976 to include screening and vaccination of women of childbearing age attending Family Planning Clinics, pregnant women, and 'other' groups. Acceptance of vaccination amongst schoolgirls has been variable with a national average of $70-75$ per cent, whilst a few Area Health Authorities have introduced screening as a routine in Family Planning Clinics. Ministry of Defence policy ${ }^{2-5}$ has been in line with the DHSS recommendations and in 1976 medical officers were 'urged' to screen female nursing staff, teachers, welfare staff and medical officers, such as Obstetricians, who might act as potential sources of infection. No other definitive instructions were given about screening of female service entrants, this being a matter of interpretation for the 1976 DHSS document ${ }^{6}$.

\section{Method}

The efficiency of the current system was assessed by a study of the following-

(a) The screening procedures undertaken at training centres for female Service entrants. (b) Training centre policies for vaccination or follow-up of seronegative recruits, and the documentation of results. (c) the recording of Rubella screening results on the medical records of Queen Alexandra's Royal Army Nursing Corps (QARANC) hospital staff in the Aldershot area. (d) Screening of personnel working in the Military Maternity Hospital, Aldershot. (e) Questionnaires to recruits at Training Centres, QARANC hospital staff, and QARANC personnel found to be seronegative.

\section{Results}

The results as at 30 September 1979 are given below. 
Screening procedures

Royal Navy. All female nursing entrants were routinely screened and vaccinated if seronegative. Detailed information on documentation and follow-up in the event of posting was not readily available.

No information was available on policies for screening of non-nursing female entrants.

Royal Air Force. A policy on routine screening was under discussion and in the interim a service was made available on individual request (routine screening commenced in January 1980).

Army. Recruits were soreened routinely at the Women's Royal Army Corps (WRAC) depot, Guildford and had been for the preceding 12-18 months. Where difficulty was found in obtaining sufficient blood for tests, priority was given to blood grouping, so that these recruits were not screened. Of 840 recruits from March to September 1979, 105 fell into this category (12.5 per cent). Of those screened 28 were seronegative ( 3.2 per cent) and two results were equivocal.

Similarly recruits at the QARANC Depot, excluding officers. were screened, and over the preceding 18 months a 4.4 per cent seronegative rate had been recorded.

There was no evidence that officer entrants to either the WRAC or QARANC were being screened at the time of this survey.

\section{Follow-up of seronegative recruits and documentation}

Both WRAC and QARANC training centres stated that basic training courses did not allow sufficient time for Rubella vaccination prior to the posting of recruits. Present immunisation time-tables include active viruses and a gap of three weeks is recommended before administration of another live virus. At present smallpox, yellow fever and poliomyelitis vaccinations take priority over Rubella. In addition the results of Rubella screen are frequently not available until the recruits have completed their basic training.

At both centres the F Med 4 was completed on the reverse with the Rubella HAI result at the bottom of the cholera column. Notices were affixed to the medical documents of seronegative recruits drawing attention to the result and leaving vaccination to be undertaken by unit medical centres after posting.

\section{Efficiency of documentation}

The F Med $4 \mathrm{~s}$ of QARANC staff at the Cambridge and Louise Margaret Hospitals were reviewed for documentation of Rubella screening results. Of 203 documents examined 150 did not contain any evidence of screening.

Immune status of obstetric unit personnel

The RAMC, Naval medical officers and QARANC personnel (midwives, general nurses and ward stewardesses), working at the Louise Margaret Maternity Hospital were screened using the Rubella HAI test. Sixty-six staff members were tested, eight doctors and 58 QARANC.

Two student midwives, both officers, were found to be seronegative. Only five members of staff were aware that they had been screened in the past and 74 per cent of medical documents had no evidence of screening.

Questionnaires

Recruits into QARANC in the months of June, July and August 1979, and 
WRAC and QARANC hospital staff were sent questionnaires asking for information on previous infection, vaccination or screening for Rubella. The results of these anonymous questionnaires are given in Tables I and II.

Nine QARANC recruits found to be seronegative at initial screening were traced and questioned as to whether or not they had been vaccinated. Seven replied as follows:-

Two were unaware of the result. Two had been vaccinated. One individual, despite asking to be vaccinated, had not succeeded in having this done. Two recruits with equivocal results had not been re-screened.

In addition Red Cross Welfare staff at the hospital did not believe that they had been screened.

Table I

Questionmaire to recruits

\begin{tabular}{|c|c|c|c|c|c|c|}
\hline Personnel & $\begin{array}{l}\text { Previous } \\
\text { (yes) }\end{array}$ & $\begin{array}{c}\text { infection } \\
(\mathrm{no} / ?)\end{array}$ & $\begin{array}{l}\text { Previous } \\
\text { (yes) }\end{array}$ & $\begin{array}{c}\text { screening } \\
\text { (no/?) }\end{array}$ & $\begin{array}{l}\text { Previous } \\
\text { (yes) }\end{array}$ & $\begin{array}{c}\text { vaccination } \\
(\mathrm{no} / ?)\end{array}$ \\
\hline WRAC & 82 & 120 & 29 & 173 & 119 & 83 \\
\hline QARANC & 14 & 14 & 1 & 27 & 20 & 8 \\
\hline Totals & 96 & 134 & 30 & 200 & 139 & 91 \\
\hline
\end{tabular}

Table II

Questionnaire to QARANC hospital staff (71 replies)

\begin{tabular}{|c|c|c|c|c|c|c|c|c|}
\hline \multirow[t]{2}{*}{ Pensonnel } & \multicolumn{2}{|c|}{$\begin{array}{l}\text { Previous } \\
\text { infection }\end{array}$} & \multicolumn{2}{|c|}{$\begin{array}{l}\text { Previous } \\
\text { screening }\end{array}$} & \multicolumn{2}{|c|}{$\begin{array}{c}\text { Previous } \\
\text { vaccination }\end{array}$} & \multicolumn{2}{|c|}{$\begin{array}{l}\text { Awareness of } \\
\text { immune status }\end{array}$} \\
\hline & (yes) & (no/?) & (yes) & (no/?) & (yes) & (no/?) & (yes) & (no/?) \\
\hline Qualified staff (SRN/SEN) & 26 & 12 & 15 & 23 & 14 & 24 & 10 & 5 \\
\hline Student/pupil nurse & 7 & 4 & 9 & 2 & 9 & 2 & 6 & 3 \\
\hline Stewardess & 8 & 14 & 5 & 17 & 16 & 6 & 3 & 2 \\
\hline Totals & 41 & 30 & 29 & 42 & 39 & 32 & 19 & 10 \\
\hline
\end{tabular}

\section{Discussion}

Most training centres are clearly attempting to screen female Service recruits for susceptibility to Rubella infection, but find it impossible to offer sero. negative individuals vaccination with present immunisation time-tables. Follow-up is delegated to unit medical centres following posting. Whilst information on the success of immunisation follow-up for WRAC personnel is not available at present, the evidence from the QARANC, where insight into the potential risks should be greater, suggests that the present system is inadequate.

Additional problems occur where recruits are not screened because it is found impossible to obtain sufficient blood at venepuncture, or samples are spoiled by spillage or contamination in transit to the central screening laboratory at Millbank. At present there is no policy for follow-up and re-screening of these individuals or those with equivocal results. In addition present policies do not include any recommendations for re-screening after vaccination to ensure sero-conversion.

Documentation of results is inadequate. Individual awareness that screening has been carried out and the results of such tests is poor. None of the medical 
officers in the obstetric unit had been screened before. This reflects both on medical staff responsible for screening and the indifference of the individuals concerned to their being at risk or acting as potential sources of infection to others.

The need for all personnel (medical, nursing, and ancillary) who may come into contact with pregnant women, to be screened and vaccinated where necessary is re-affirmed. Recent changes in General Nursing Council regulations mean that male trainee nurses must participate in an obstetric course during their training. These individuals will also need screening, especially as the national pattern of natural immunity between male and females is changing as a result of the DHSS programme of school vaccination. ${ }^{6}$

\section{Recommendations}

(a) All servicewomen and RAMC personnel should be screened for Rubella immunity and vaccinated where necessary.

(b) Results should be recorded on the cover of F.Med 4 at the bottom of the Cholera column, as this inoculation is now infrequently needed.

(c) Where initial screening is unsatisfactory or equivocal results obtained, procedures should be established to ensure that re-screening takes place.

(d) Following vaccination individuals should be re-screened after six months to ensure sero-conversion.

(e) The centralisation of screening records with feed-back on follow-up should be organised to ensure that vaccination and re-screening is carried out when necessary. Ideally the system should be computerised, similar systems have been in operation with the National Health Service for many years and are highly successful. Furthermore, it would be a relatively simple matter to extend such a programme to cover all vaccination procedures and the general medical/dental status of units, providing immediate and comprehensive data on medical fitness for role.

(f) Medical or nursing personnel refusing screening or vaccination should not be employed in obstetric and gynaecological departments or their associated clinics.

(g) The instructions for screening and vaccination in the "Memorandum on Immunological Procedures" JSP 311, paras 269-275 should be revised in accordance with paras (a) to (f) above.

(h) Efforts should be made to ensure that members of welfare services at home and abroad are screened and vaccinated where necessary.

\section{REFERENCES}

1. Hanshaw, J B and Dudgeon, J A (1978). Rubella. Major Problems in Clinical Paediatrics (Philadelphia) 17, 17-96.

2. Ministry of Defence (1976). Laboratory investigations of viral, rickettsial and chlamydial diseases. D/AMD/60/4/5/AMD5c. 19 January

3. Ministry of Defence (1976). Vaccination against measles and rubella. D/AMD/4/2/1! AMD5. 12 October.

4. Ministry of Defence (1968). Immunisation procedures-Rubella vaccination. D/AMD/ 60/6/1D/AMD5. 1 June.

5. Ministry of Defence. Memorandum on immunological procedures. JSP 311. Paras 269275. (Amdt 4. 1 Nov. 79).

6. Department of Health and Social Security (1976). Rubella vaccination. CMO (76) 4.

7. Clarke, M SCHILD, G C, BouStred, J et al (1979). Effect of rubella vaccination programme on serological status of young adults in United Kingdom. British Medical Journal i, 1224-1226. 